\title{
Power electronic loads with negative differential impedance in a low voltage distribution system
}

\section{Citation for published version (APA):}

Heskes, P. J. M., Myrzik, J. M. A., \& Kling, W. L. (2009). Power electronic loads with negative differential impedance in a low voltage distribution system. In Proceedings of the 20th International Conference and Exhibition on Electricity Distribution (CIRED), 8-11 June 2009. Prague, Czech Republic (pp. 0549-1/4). (IET Conference Publications; Vol. 550). Institution of Engineering and Technology (IET).

https://doi.org/10.1049/cp.2009.0830

DOI:

10.1049/cp.2009.0830

Document status and date:

Published: 01/01/2009

\section{Document Version:}

Publisher's PDF, also known as Version of Record (includes final page, issue and volume numbers)

\section{Please check the document version of this publication:}

- A submitted manuscript is the version of the article upon submission and before peer-review. There can be important differences between the submitted version and the official published version of record. People interested in the research are advised to contact the author for the final version of the publication, or visit the $\mathrm{DOI}$ to the publisher's website.

- The final author version and the galley proof are versions of the publication after peer review.

- The final published version features the final layout of the paper including the volume, issue and page numbers.

Link to publication

\section{General rights}

Copyright and moral rights for the publications made accessible in the public portal are retained by the authors and/or other copyright owners and it is a condition of accessing publications that users recognise and abide by the legal requirements associated with these rights.

- Users may download and print one copy of any publication from the public portal for the purpose of private study or research.

- You may not further distribute the material or use it for any profit-making activity or commercial gain

- You may freely distribute the URL identifying the publication in the public portal.

If the publication is distributed under the terms of Article 25fa of the Dutch Copyright Act, indicated by the "Taverne" license above, please follow below link for the End User Agreement:

www.tue.nl/taverne

Take down policy

If you believe that this document breaches copyright please contact us at:

openaccess@tue.nl

providing details and we will investigate your claim. 


\section{POWER ELECTRONIC LOADS WITH NEGATIVE DIFFERENTIAL IMPEDANCE IN A LOW VOLTAGE DISTRIBUTION SYSTEM}

\author{
P.J.M. Heskes \\ Energy research Centre of the \\ Netherlands (ECN) \\ heskes@ecn.nl
}

\author{
J.M.A. Myrzik \\ Technical University of Eindhoven \\ the Netherlands \\ J.M.A.Myrzik@tue.nl
}

\author{
W.L. Kling \\ Technical University of Eindhoven \\ the Netherlands \\ W.L.Kling@tue.nl
}

\begin{abstract}
Today's domestic appliances are more and more adapted and controlled by power electronics and processors, and their number is growing. This development can bring both advantages and disadvantages for the power quality in local grids. An advantage for example is the growing number of power supplies that are equipped with a Power Factor Corrector front-end. This type of power supply behaves as a resistive load and has a very good power factor. A disadvantage for example is the constant power load character that comes with a controlled $A C$ to $D C$ power supply with a constant loaded DC output, independent of the applied grid voltage. This type of load has a Negative Differential Impedance (NDI) and can cause voltage instability. This paper discusses the NDI effect that power supplies can bring, and their effect on voltage stability.
\end{abstract}

\section{INTRODUCTION}

Today's appliances that are equipped with a power electronic converter can show a Negative Differential Impedance (NDI) behaviour, which is caused by the converter control system. NDI can cause voltage instability. Other voltage instability effects in the grid, are noticed with inverters for photo voltaic systems. They can bring a negative absolute impedance to the grid in the harmonic frequency range. This effect can gain harmonic voltages in the grid [01]. This paper focuses only on the NDI of power supplies, and their effect on voltage stability.

Impedance is called to be negative, when the real part of the complex impedance is negative. To get more insight in possible voltage instability with this, a general equation for a linear transfer function in the Laplace domain is given in (1), [02].

$$
H(s)=k \frac{\prod_{p=1}^{m}\left(s-z_{p}\right)}{\prod_{q=1}^{n}\left(s-p_{q}\right)}
$$

Wherein $s=\lambda+j \omega$ is the complex frequency variable, $\mathrm{z}_{\mathrm{p}}$ the zeros and $\mathrm{p}_{\mathrm{q}}$ the poles of the transfer function. Due to the fact that physical systems cannot increase the response to infinite with a frequency rising to infinite, the order of the numerator must be equal or less then that of the denominator, so $n \geq m$ in (1).

The voltage instability effect that can show up from this transfer function $H(s)$, is that the transition from one output state to a new state, will not be damped to zero, but starts with an increasing oscillation. A remarkable thing is that if the transfer function is taken the opposite way, from voltage to current, impedance will be turned into admittance, and poles will turn into zeros and the other way round, zeros will turn into poles. With this a stable system can become unstable. An example of this is the fluorescent lamp, that cannot be driven in a stable way directly (without a ballast) from a voltage source, but however can be driven in a stable way directly from a current source [03].

\section{VOLTAGE STABILITY}

To get more insight in voltage stability criteria, there must be focussed on the poles $p_{q}$ in the denominator of (1). Poles in general are complex, and if the imaginary parts equals zero, the pole only has a real part. For each complex pole, a complex conjugate pole will also bring a solution. The contribution of a pair of poles to the output of the transfer function in the time domain $F(t)$ will be in the form of:

$$
\begin{aligned}
& F(t)=c e^{p_{q} t}+c^{*} e^{p_{q} t} \\
& F(t)=c e^{(\lambda+j \omega) t}+c e^{(\lambda-j \omega) t} \\
& F(t)=c e^{\lambda t} e^{ \pm j \omega t}
\end{aligned}
$$

Wherein $e^{\lambda t}$ represents the damping of the system and $c e^{ \pm j \omega t}$ the steady state condition. $F(t)$ tends to a stable steady state condition if $\lambda<0$ for all parts that contribute to the output.

The first role for a transfer function $H(s)$ that will tend to a stable steady state condition is that the real part of the roots of $H(s)$ must be negative, in other words, the poles of $H(s)$ must fall in the left half-plane of the Pole-Zero 
$\operatorname{map}[02]$.

As an example, in figure 1, three possible real poles of the first order transfer function of (5) are depicted in a PZ-map and the corresponding step-responses of $H_{1}(s)$ are drawn above the poles. Also three possible complex pair of poles of the second order transfer function of (6) are depicted in this PZ-map and here the corresponding step-responses of $H_{2}(s)$ are drawn above the upper poles.

$$
\begin{aligned}
& H_{1}(s)=k \frac{s}{s-p} \\
& H_{2}(s)=k^{\prime} \frac{s}{\left(s-p_{1}\right)\left(s-p_{2}\right)}
\end{aligned}
$$

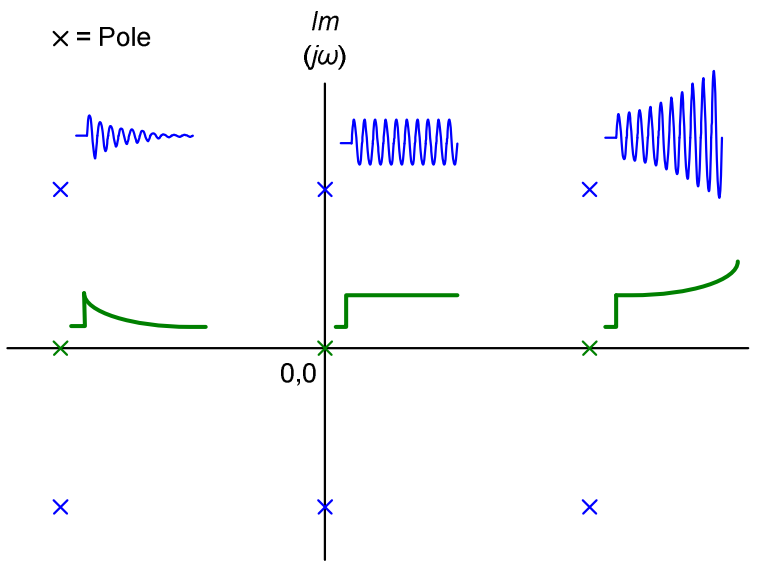

Figure 1, PZ-map and step-responses of a first-and second order system, resp. plotted in green and blue.

Poles that lie in the right half-plane of the PZ-map have a positive real part and indicate instability. However these poles can be compensated by placing zeros on the same positions, this action will change the total transfer function and instability is removed.

The impedance of the grid at a certain point will be defined by a number of parallel and series impedances in the surrounded area, depending on the network structure. Assume that there are appliances in the grid that show a negative impedance value, then these particular impedances can reduce the damping in the system which results that poles are shifted towards the positive real half-plane. If the number of this kind of impedances rises significantly, at least poor damped resonances or even voltage instability might occur.

\section{Absolute and differential impedance}

In figure 2, the V-I curves of two typical loads are given. The left side figure could be that of an incandescent lamp, where the blue dashed line is the absolute impedance for a certain operating point that depends on the applied RMS voltage, and the red line the positive differential impedance, in that operating point. The right side figure could be that of a power supply, which shows a NDI.
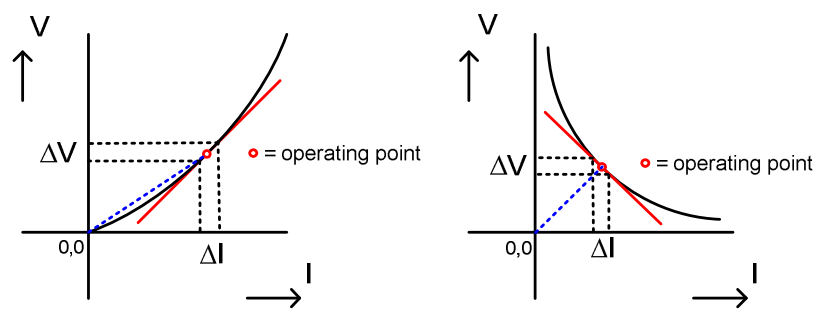

Figure 2, Black: VI curve, Blue dashed: absolute impedance, Red: differential impedance.

Absolute impedance can also be negative [01], this is shown in figure 3 , however this cannot exist with a single physical component, also an energy source is required.

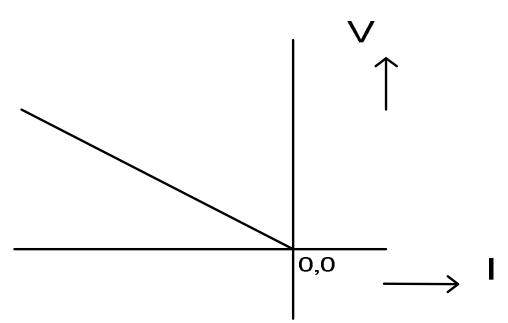

Figure 3, A negative absolute impedance.

In general it can be said that loads or sources connected to the grid with power electronic converters have the potential to show a negative absolute as well as a NDI, for certain frequencies. This can lead to voltage instability [04].

\section{Differential impedance}

The differential impedance of a grid connected appliance is the impedance that shows up when the operation point changes. This differential impedance counts for deviations on a bias signal. The bias signal can for example be the grid fundamental and the deviations can be a slow variation like a flicker distortion, a sub-harmonic or an oscillation.

Grid connected appliances work in a certain operation point and for each operating point, the impedance can be different. Appliances that can be specified with only one impedance figure for all operating points, are special loads. Pure linear components without saturation effects comply with this. For example, a pure resistor has the same impedance for all frequencies in all operating points, here the absolute and differential impedance is just the resistor value. However, this is not the case in general in practice; even an incandescent lamp is not linear due to the temperature dependence of the filament resistance. This temperature effect is a slow process, therefore the differential impedance appears at slow varying voltages.

Because the differential impedance of non-linear loads depends on the operation point, it is very important to know 
that this differential impedance only can be seen as linear for small signals around this operation point.

\section{Constant power load}

A load that needs special attention is the constant power load. Just as non-linear loads in general, the impedance depends on the applied voltage. In practice a lot of domestic appliances are loads with AC to DC converters inside, feeding an internal part that works on a constant direct voltage that feeds the internal load. The control system of these AC to DC converters controls the direct voltage $\mathrm{U}_{\mathrm{dc}}$ in a way that the voltage is independent of the applied grid voltage $U_{a c}$, see figure 4 . This implies that the AC power remains constant if the grid voltage varies. If the grid voltage increases, the grid current will decrease and also the other way round, if the grid voltage decreases, the grid current will increase. This behaviour brings a NDI.

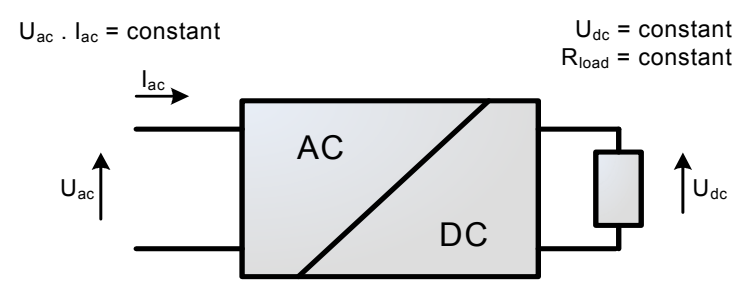

Figure 4, a constant power load

\section{Measurement on a constant power load}

In figure 5 , the $\mathrm{V}_{\mathrm{RMS}}-\mathrm{I}_{\mathrm{RMS}}$ curve of a PC $+\mathrm{LCD}$ screen is plotted, this curve is measured in a laboratory set-up with a grid simulator and power analyser. The curve shows a constant power load with NDI.

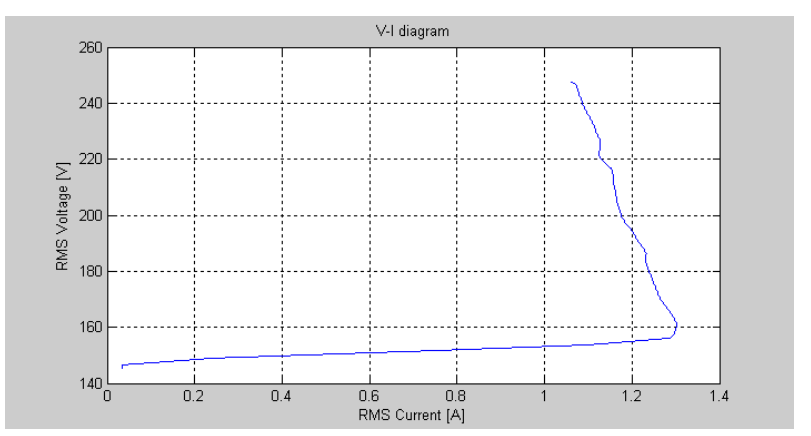

Figure 5, $V_{R M S} I_{R M S}$ curve of a PC $+L C D$ screen, a constant power load with a NDI.

For this measurement the supply voltage was ramped down from $250 \mathrm{~V}_{\mathrm{RMS}}$ to $145 \mathrm{~V}_{\mathrm{RMS}}$ in $500 \mathrm{~ms}$ time. During this ramp the RMS voltage and current was measured. As can be seen in the figure, the differential impedance around the normal operating point of $230 \mathrm{~V}_{\mathrm{RMS}}$, is negative. This constant power load behaviour is expected, because the internal electronics of the PC + LCD screen are both fed by a power supply which controls its DC output voltage.
Figure 6, shows a typical control system of a power supply with a constant power load with a NDI. The frequency band where this differential impedance exists, is a process with a certain response time that depends on the transfer functions and internal parts of the power supply.

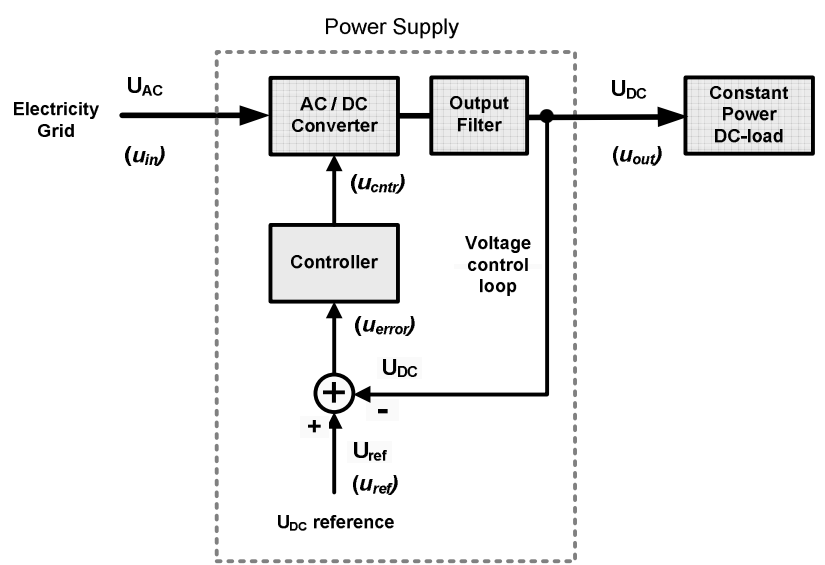

Figure 6, Typical control system of a constant power load converter, with a NDI.

The closed loop transfer function from $u_{\text {ref }}$ to $u_{\text {out }}$ is given in (10) and a Bode magnitude plot in figure 7. To get an idea of the effect of the control system on the differential impedance, the closed loop transfer function from $u_{\text {in }}$ to $u_{\text {out }}$ is given in formula (12) and also a Bode magnitude plot in figure 8 . These functions are built up as follows:

In the following example, the controller function, $u_{\text {error }}$ to $u_{\text {cntr }}$ is:

$$
H_{1}\left[\frac{u_{\text {cntr }}}{u_{\text {error }}}\right]=k_{1} \frac{\left(s \tau_{c}+1\right)^{2}}{s \tau_{c}}
$$

The transfer function of the AC to DC converter, from $u_{\text {cntr }}$ to $u_{\text {out }}$ is $H_{2}\left[\frac{u_{\text {out }}}{u_{\text {cntr }}}\right]$, this is the modulation index $k_{2}$ times the internal bus voltage $\mathrm{U}_{\mathrm{DC} \text { BUS }}$, which depends on $\mathrm{U}_{\mathrm{AC} \text { RMS. }}$ The voltage $\mathrm{U}_{\mathrm{DC}}$ BUs is here assumed to be a constant $k_{3}$, this only count for small-signal analysis. The output filter is chosen to be of a second order type: $\frac{1}{\left(s \tau_{f}+1\right)^{2}}$, so:

$$
H_{2}\left[\frac{u_{o u t}}{u_{c n t r}}\right]=k_{2} k_{3} \frac{1}{\left(s \tau_{f}+1\right)^{2}}
$$

$\tau_{c}$ is chosen to be equal to $\tau_{f}$, then the round going loopgain of the system is:

$$
\stackrel{0}{H}=k_{1} k_{2} k_{3} \frac{1}{s \tau_{f}}=k_{t o t} \frac{1}{s \tau_{f}}
$$

The closed-loop transfer function $u_{r e f}$ to $u_{\text {out }}$ is in this case: 


$$
H\left[\frac{u_{\text {out }}}{u_{\text {ref }}}\right]=\frac{H_{1} H_{2}}{1+H}=\frac{\stackrel{0}{H}}{1+\stackrel{0}{H}}=\frac{1}{s \frac{\tau_{f}}{k_{\text {tot }}}+1}
$$

To estimate the frequency band where a differential or absolute impedance exists, presentation in the $j \omega$ domain will be sufficient. This means that the $\lambda$ part of the complex frequency $\lambda+j \omega$, is left out. This also means that only the steady-state modus is depicted, the damping of the system cannot be seen.

The Bode magnitude plot of figure 7 shows a roll-off frequency in the $j \omega$-domain, equal to $\frac{k_{t o t}}{\tau_{f}}$ from (10). This means that $u_{\text {out }}$ can follow $u_{\text {ref }}$ up to this point, roughly without reduction.

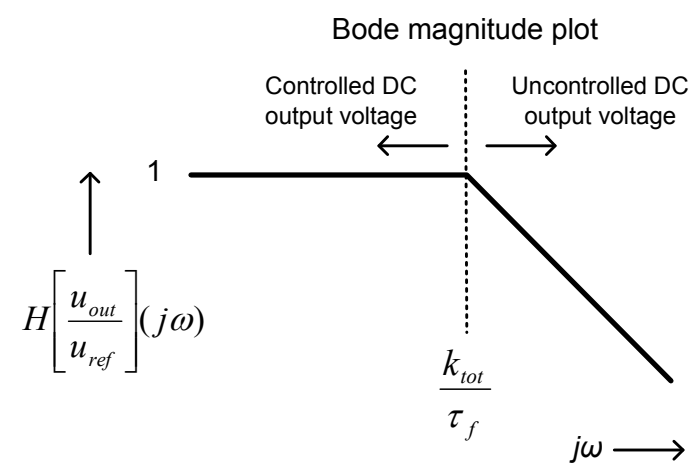

Figure 7, Bode magnitude plot of (10)

To get more insight in the area where a differential impedance exists and also the part where an absolute impedance exists, the closed-loop transfer function from $u_{\text {in }}$ to $u_{\text {out }}$ and a Bode magnitude plot is given in equation (12) and figure 8 . To find this figure, the closed-loop transfer function is derived below.

The open-loop transfer function from $u_{\text {in }}$ to $u_{\text {out }}$ is:

$$
H_{2}^{\prime}\left[\frac{u_{\text {out }}}{u_{\text {in }}}\right]=k_{2} \frac{1}{\left(s \tau_{f}+1\right)^{2}}
$$

And the closed-loop:

$$
H\left[\frac{u_{\text {out }}}{u_{\text {in }}}\right]=\frac{H_{2}^{\prime}}{1+\stackrel{0}{H}}=k_{2} \frac{s \frac{\tau_{f}}{k_{\text {tot }}}}{s \frac{\tau_{f}}{k_{\text {tot }}}+1} \frac{1}{\left(s \tau_{f}+1\right)^{2}}
$$

The first part of expression (12) shows the active filtering of $u_{\text {in }}$ towards $u_{\text {out }}$ by the control system and the second part shows the passive filtering of the output filter of the converter. For simplicity, the effect of the output filter, the second part of expression (12), is neglected in figure 8. At the frequency where the figure overturns, the control system is no longer able to limit grid voltage changes in $u_{\text {out }}$. It is this point where the negative differential behaviour stops, this also equals $\frac{k_{t o t}}{\tau_{f}}$.

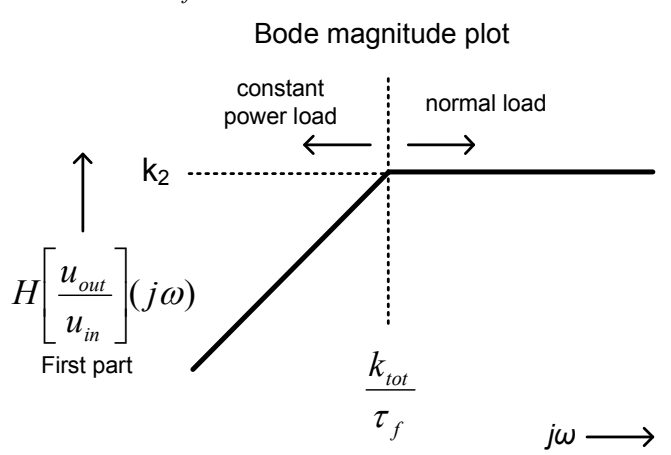

Figure 8, Bode magnitude plot of the first part of (12)

In this simplified figure, the large influence of the output filter and also the buffer capacitor impedance is not taken into account. But based on Matlab/Simulink simulations it can be said that NDI show up at frequencies below the fundamental grid frequency.

\section{CONCLUSIONS}

The NDI of constant power loads has only voltage stability effect at frequencies below the grid fundamental frequency, therefore there is no such effect at harmonic frequencies.

The possible impact on low frequency voltage instability due to NDI is however not very likely, because to enter the area of voltage instability, existing impedances in the system must start resonating at these low frequencies. In this sense the growing numbers of power electronic appliances in local distribution areas, needs attention, but will not yet lead to instability problems

\section{ACKNOWLEDGMENT}

This work is supported in part by SenterNovem under Grant EOSLT04024.

\section{REFERENCES}

[01] P.J.M. Heskes, J.F.G. Cobben, H.H.C. de Moor "Harmonic distortion in residential areas due to large scale PV implementation is predictable" International Journal of DER, Vol. 1, No. 1, 2005.

[02] J.C.Cool, F.J. Schrijf, T.J. Viersma, Control technics, Study book, Agon Elsevier, 1972.

[03] E. Deng ${ }^{1}$, S. Cuk ${ }^{2)}$, Negative Incremental Impedance and Stability of Fluorescent Lamps, ${ }^{1)}$ GE Corporate R\&D, New York, USA, ${ }^{2)}$ California Institute of Technology, California, USA, IEEE, 1997.

[04] A. Emadi, Modeling of Power Electronic Loads in AC Distribution Systems, USA, Transactions on Industrial Electronics, Vol. 51, No.5, 2004. 